\title{
FATORES QUE PRODUZEM EVASÃO ACADÊMICA NO CURSO DE CIÊNCIAS CONTÁBEIS DA UNEMAT DE TANGARÁ DA SERRA/MT
}

\author{
Karen Cristina Honório Cardoso Sauberlich ${ }^{1}$
}

\section{RESUMO}

Este estudo se propôs a investigar e conhecer os fatores motivadores para a evasão acadêmica no curso de Ciências Contábeis da Universidade do Estado de Mato Grosso, campus de Tangará da Serra, tendo como sujeitos os acadêmicos com entrada nos vestibulares 2008/1 a 2011/2. A amostra foi estabelecida com 67 alunos evadidos do curso no período descrito, de forma que destes obteve-se retorno de $47,76 \%$ o que corresponde a 32 entrevistados. O perfil dos entrevistados assim se caracterizou: em sua maioria são do sexo feminino, cursaram o ensino médio em escola pública, evadiram ainda no primeiro ano de curso e não reprovaram nenhuma vez em qualquer disciplina. Foram apontados como principais fatores motivadores para a evasão, as condições de trabalho e falta de tempo para estudar e fazer as atividades curriculares.

Palavras chave: Ensino Superior, Contabilidade, Evasão Universitária.

\section{INTRODUÇÃO}

O curso de Ciências Contábeis da Universidade do Estado de Mato Grosso UNEMAT - campus de Tangará da Serra/MT, tem o objetivo de capacitar e formar os acadêmicos do curso para que se tornem profissionais aptos para o exercício da profissão contábil com qualidade e responsabilidade. Desde sua origem em 1990 o curso é destaque na cidade e região, de modo que dados estatísticos demonstram o quanto o curso é cada vez mais concorrido em se tratando de busca de vagas disponibilizadas para Concurso Vestibular: em 2008/1 a concorrência foi de 8,8 candidatos por vaga, em 2009/2 a concorrência ficou em 6,3 candidatos por vaga, 2011/1 a concorrência foi de 7,9 pessoas por vaga e em 2011/2 foi de 7,6 candidatos por vaga (COVEST, 2012) .

Apesar de tal índice de concorrência, é possível se perceber que há um número considerável de acadêmicos que acabam desistindo do curso antes de terminá-lo. Para isso basta percorrer os corredores da Universidade e observar as salas de aulas, que em geral, não se apresentam com a lotação imaginada.

Semestralmente são oferecidas 50 vagas em concurso vestibular para o curso de Ciências Contábeis, em duas entradas, num total de 100 vagas anuais. Entretanto, é possível se perceber que o número de acadêmicos por turma vem diminuindo a cada semestre. Tal fato

\footnotetext{
${ }^{1}$ Acadêmica do curso de Ciências Contábeis da UNEMAT - Campus de Tangará da Serra, e-mail: karencristina_cardoso@ hotmail.com . orientada pela Prof ${ }^{a}{ } r^{a}$ Maria Helena Rodrigues Paes do Departamento de Letras da UNEMAT- Universidade do Estado de Mato Grosso, campus de Tangará da Serra/MT. E-mail: ninhapaes@unemat.br.
} 
observado é devido á vivência diária desta pesquisadora como acadêmica no referido curso a partir de 2008/1. Ou seja, o número de concluintes do Curso de Ciências Contábeis tem registrado números significativamente menores de acadêmicos concluintes em relação ao número de vagas disponíveis.

Dado o exposto, surge a seguinte questão: que fatores têm provocado o fenômeno da evasão acadêmica no curso de Ciências Contábeis da UNEMAT de Tangará da Serra/MT a partir de 2008/1? Diante de tal problemática, o objetivo geral da pesquisa aqui relatada consistiu em identificar os fatores que produzem evasão acadêmica no curso de Ciências Contábeis no campus de Tangará da Serra-MT entre o período de 2008/1 a 2011/2. Quanto aos objetivos específicos procurou-se: Conhecer o índice de evasão dos cursos da Universidade do Estado de Mato Grosso, em especial, do Campus de Tangará da Serra; Levantar dados de alunos evadidos do curso de Ciências Contábeis da UNEMAT de Tangará da Serra/MT no período de 2008/1 a 2011/2 e caracterizar o perfil dos evadidos do curso.

Assim, este trabalho visa expor à comunidade acadêmica os fatores que levaram os alunos ingressos no curso em questão a evasão deste, nos períodos já descritos, além de apresentar grande relevância para a formação acadêmica desta pesquisadora. Tal estudo só virá a contribuir com a Universidade, pois conhecendo os fatores que provocam o fenômeno da evasão será possível se construir políticas de adequação que possam apontar caminhos e soluções ara combater o fenômeno da evasão.

\section{REFERENCIAL TEÓRICO}

\subsection{A Contabilidade}

Pode se encontrar em Sá (2002) informações que nos dão a compreender que mesmo antes da descoberta da escrita e dos cálculos, o homem criou uma forma primitiva de inscrição baseada na arte, através da qual ele demonstrava fatos de seu cotidiano e também registrava dados sobre suas posses. Os desenhos do homem primitivo eram realizados em paredes de grutas e cavernas assim como em ossos e pedras. Há indícios desta arte, conhecida como rupestre, em países da Europa e também no Brasil. O que frequentemente desenhavam eram formas de animais, que representavam suas riquezas e os desenhos de "risquinhos" representavam a quantidade que pertenciam ao desenhista.

Com o passar do tempo, seguindo o mesmo autor, as riquezas aumentavam, o que fazia com que as inscrições do homem se tornassem mais complexas, e tal fato o obrigava a buscar técnicas mais aprimoradas, fazendo surgir às primeiras escriturações contábeis para demonstrar e quantificar as riquezas conquistadas. Esta fase ainda primitiva foi a que deu 
início a história da contabilidade, uma história que se tornaria ao longo dos anos mais complexa e se tornaria mais tarde uma ciência.

Milhares de anos depois a atividade comercial, conforme Sá (2002), intensificou a troca de produtos entre as pessoas, gerando várias movimentações diárias, o que fez surgir a necessidade de desenvolver a escrita contábil. Precisava-se saber ao certo o que se deveria receber e o que se deveria pagar, surgindo à idéia de "meu" (o que os outros me devem) e de "seu" (o que lhe devo pagar), automaticamente originando o débito e o crédito, ponto inicial da matéria contábil. Diante deste fato a escrita contábil evoluiu e deu origem a escrita comum.

Passados vários anos de aprimorametos a era primitiva ficou para trás e deu lugar ao que chamamos de antiguidade clássica (aproximadamente nos anos de 1050 d.C. a 1300 d.C.), sendo que nesta época a contabilidade ainda estava limitada apenas a registros e poucas normas, porém já era ensinada nas escolas acompanhando os cálculos matemáticos. A evolução da contabilidade foi uma conseqüência dos inúmeros fatos a se registrar, da evolução socioeconômica somada à qualidade da escrita dos escribas e matemáticos voltados à contabilidade (SÁ, 2002).

De acordo com Oliveira et al (2003), o surgimento da moeda também foi um marco para a história da Contabilidade, quando os meios de troca se equipararam e os valores se tornaram uniformes, fazendo surgir a moeda no século VII na Europa. No Egito também foram encontrados registros de contabilidade, naquele território foi onde surgiu o papiro, e este sofisticou a elaboração dos registros contábeis, pois foi possível descrever no papiro as técnicas da época, os desenhos de animais foram substituídos por sinais gráficos, primeiro em folhas soltas depois as agrupando e formando livros e coletâneas. Por volta de 2000 anos a.C. no Egito já era obrigatório os livros e documentos comerciais, fato que levou os egípcios ao uso continuo da contabilidade, e os obrigavam a escriturar as movimentações comerciais com base no valor de sua moeda progredindo também o aspecto econômico do lugar.

Na Grécia, conforme Oliveira, et. al (2003), os registros contábeis foram elaborados em tábuas de argila, de forma que através destes registros foi comprovado que as atividades agrícolas predominavam nos anos de 2100 a 1580 a.C. e que o Estado era quem controlava toda a produção. Foi na Grécia que localizaram um dos documentos contábeis mais evoluídos da antiguidade, com data de 454 a 406 anos a.C., em cujo documento estavam relacionados todos os contribuintes de impostos do império grego, o que demonstra controle do recebimento de impostos e prestação de contas ao público. 
Em 1494, na cidade de Veneza, foi impresso o primeiro trabalho na área de contabilidade, uma obra que transcreveu os pensamentos do frei Luca Pacioli a respeito do método de partidas dobradas "La Suma de Arithmetica, Geometria, Proportioi et Proportionalita”, grande marco da história da contabilidade. A obra se difundiu de tal maneira que este método foi várias vezes chamado de método italiano e a partir desta, várias outras obras começaram a surgir na Itália e em diversos países, cujo marco histórico foi chamado de Escola Italiana (SÁ, 2002).

Os processos contábeis foram muito estudados para que a contabilidade pudesse ser reconhecida como ciência, já que para isso deveria atender a alguns requisitos para ser classificada de tal forma, como por exemplo, ter objeto, finalidade, método específico, teorias, etc. Estudos demonstram que o objeto da contabilidade é o patrimônio e a finalidade se configura na satisfação de seus usuários através de informações precisas para a tomada de decisões. Um dos métodos da contabilidade é o da observação para a condução de pesquisas, as quais versam e expressam várias teorias como: teoria do valor, teoria geral do conhecimento, teoria do patrimônio, assim a contabilidade foi reconhecida como ciência em 1846 (SÁ, 2005).

Para o reconhecimento da contabilidade como ciência, foi entendimento de pensadores contábeis que o registro contábil era apenas a transcrição da movimentação das riquezas patrimoniais, mas não era o fato em si. Escriturar apenas não bastava, era preciso entender o que fazer com as informações obtidas, saber o que as escriturações realmente demonstravam em relação à mutação patrimonial. Com tal compreensão a contabilidade começou a se diferenciar e passou a se caracterizar como um grande instrumento de compreensão da realidade e contexto contábil para a tomada de decisões por parte de quem governava as riquezas. O estudo científico da contabilidade se dedica, então, a entender o que realmente ocorre com a riqueza patrimonial e de onde derivam suas transformações. Com estudos e teorias o contador deixou de ser um informante para ser um orientador de empreendimentos (SÁ, 2005).

A classificação científica da contabilidade se enquadra como factual (também denominada material ou empírica), sendo que o que caracteriza a contabilidade como ciência social é o fato do homem/sociedade ter efeito sobre o patrimônio das entidades. Fatores sociais combinados com os usuários da contabilidade influenciam nos estudos e em sua matéria e teorias, além de modificar e interpretar os fenômenos contábeis. A utilização de conhecimentos adquiridos ao longo da história, para solucionar problemas, definir objetivos e 
usar suas informações para fins gerenciais torna a contabilidade uma ciência aplicada (SANTOS, et al., 2003; OLIVEIRA, et al., 2003).

\subsubsection{O curso de Ciências Contábeis no Brasil}

O curso de Ciências Contábeis foi criado através do Decreto Lei $\mathrm{N}^{\circ} 7.988$ em 22 de Setembro de 1945, o qual se denominava curso de Ciências Contábeis e Atuariais. Passou funcionar em 1946 na faculdade de Ciências Econômicas e Administrativas na USP. Através do Decreto Lei No 9295 de 27 de Maio de 1946 foi criado o Conselho Federal de Contabilidade - CFC, o qual determinou e subdividiu as atribuições dos profissionais de contabilidade no Brasil, fato que impulsionou o avanço da contabilidade no país. Juntamente com o CFC foram criados os Conselhos de Contabilidade (CRC) para em conjunto fiscalizar o exercício da profissão (FIGUEIREDO; FABRI, 2000). A Lei No 1401 de 31 de Julho de 1951 dividiu o curso de Ciências Contábeis e Atuariais em dois cursos: Ciências Contábeis e Ciências Atuariais conferindo assim o grau de bacharel para ambos os cursos (PELEIAS et al., 2007).

Ainda no ano de 1946 o país ganhou seu primeiro núcleo de pesquisa contábil, onde professores dedicavam-se inteiramente ao ensino e pesquisa da contabilidade. Nesta época foram escritos trabalhos acadêmicos de grande prestígio para o Brasil. Um estudo de grande repercussão foi escrito por Francisco D' Áuria em 1948 o qual se intitula: "Primeiros princípios de contabilidade pura", esta obra diz respeito a conceitos e finalidades da contabilidade como ciência (FIGUEIREDO; FABRI, 2000; IUDÍCIBUS, 2000; REIS; SILVA, 2007).

Embora a contabilidade enquanto ciência tenha se inscrito em nossa sociedade a partir de 1945, o pensamento contábil já era ensinado no Brasil através da Escola de Comércio Álvares Penteado, fundada em 1902 em São Paulo, a qual baseava-se no modelo da escola italiana, que formou professores de grande destaque, como por exemplo: Francisco D' Áuria e Frederico Herrmann Júnior. Ainda hoje se observa no Brasil pesquisadores com características da escola italiana, principalmente em Minas Gerais, já em determinados ramos da contabilidade, como por exemplo, a Auditoria, nota-se influência predominante da escola norte americana. (FIGUEIREDO; FABRI, 2000; IUDÍCIBUS, 2000)

\subsubsection{O curso de Ciências Contábeis na UNEMAT campus Tangará da Serra/MT}

Ao iniciar esta seção cabe anunciar ao leitor que as informações nela apresentadas constam na página oficial do Departamento de Ciências Contábeis da Universidade do Estado 
de Mato Grosso, do campus de Tangará da Serra. Ressalta-se ainda que tais informações também fazem parte do Projeto Político Pedagógico do citado curso.

O curso de Ciências Contábeis na UNEMAT de Tangará da Serra/MT visa formar contadores capacitados e qualificados para exercerem sua profissão, dotados de senso analítico crítico. A instituição tem como objetivo contribuir de forma competente para o desenvolvimento das sociedades, visto que oferece estrutura e apoio aos cursos que formam profissionais atuantes, que colaboram com o desenvolvimento e progresso de nossa nação.

O curso de Ciências Contábeis iniciou suas atividades em 5 de Março de 1990, autorizado através do Decreto $\mathrm{N}^{\circ} 99.023$ que lhe conferiu autorização de funcionamento. $\mathrm{Na}$ época o curso era oferecido e mantido pelo Centro de Ensino Superior de Tangará da Serra CESUT e ministrado pela Faculdade de Ciências Contábeis e Administração de Tangará da Serra - FACCATS.

Em 04 de Abril de 1995, conforme Resolução Nº 010/94 da Fundação Universidade do Estado de Mato Grosso e aprovação do Conselho Estadual de Educação - CEE/MT, os cursos de ensino superior do CESUT passaram a ser mantidos pelo Sistema Estadual de Ensino. A partir de tal acontecimento a UNEMAT encampa a CESUT e dá continuidade as atividades dos cursos de nível superior, agora contando com novas estruturas e novas políticas de ensino. Ainda no ano de 1995, no mês de setembro, passa a funcionar o Departamento de Ciências Contábeis no campus Tangará da Serra/MT. Um trabalho foi realizado na mesma época a respeito do processo de discussão e avaliação sob a visão dos docentes e discentes, buscando dar um enfoque dinâmico às atividades mantendo os objetivos institucionais do curso.

O departamento do curso realizou com êxito em Outubro de 1997 a I Semana de Ciências Contábeis da UNEMAT no Centro Cultural do município, objetivando dar oportunidade aos acadêmicos, futuros contadores, em construir novos conhecimentos através de palestras e debates com grandes profissionais da área contábil. $\mathrm{O}$ evento repercutiu de tal maneira que é repetido anualmente. O curso de Ciências Contábeis foi reconhecido através da Portaria $n^{\circ}$ 875/98 pela SEDUC - Secretaria Estadual de Educação em 19 de Outubro de 1.998 .

Em Agosto de 2000 foi oferecido o primeiro curso de Pós-Graduação latu-sensu, tendo como título: Especialização em Finanças e Gestão Empresarial, oferecendo 50 vagas. O segundo curso de especialização foi oferecido em 2002: Finanças, Controladoria $e$ Auditoria. Também em 2002 foi montado o laboratório contábil do campus, contando com 12 
micros computadores e 2 programas de contabilidade (Mastermaq e Gecon). $\mathrm{O}$ terceiro curso de especialização latu-sensu ocorreu em 2004 ofertando pela segunda vez Finanças e Gestão Empresarial.

A partir de 2005 os cursos da UNEMAT foram reestruturados e passaram a ser semestrais, com isso dobraram as vagas disponibilizadas por ano, dando possibilidade a mais pessoas em ingressar em nível superior. O curso de Ciências Contábeis é o único do campus de Tangará da Serra/MT que oferta 50 vagas por vestibular, sendo também o mais concorrido dentro os cursos, conforme já registrado acima. No vestibular 2008/1 a concorrência foi de 7,5 concorrentes por vaga, em 2008/2 concorrência foi de 7,1 candidatos por vaga, já em 2009/1 foi de 7,2 por candidatos vaga, em 2009/2 a concorrência foi de 8 pessoas para cada vaga ofertada, em 2010/1 a concorrência caiu um pouco e ficou em 6,9 candidatos por vaga, voltou a ficar mais concorrido no vestibular 2010/2 com 7,5 pessoas por vaga. No primeiro vestibular de 2011 a concorrência foi de 7,4 candidatos por vaga, sendo que no segundo semestre do mesmo ano houve novidades para os vestibulandos, já que os candidatos podiam se inscrever para duas opções de curso. Diante de tal condição, a concorrência se elevou muito e chegou a 14,3 pessoas por vaga, dentre os inscritos para Ciências Contábeis como primeira e segunda opção (UNEMAT, 2011).

\section{Evasão no ensino superior}

Entende-se por evasão um fenômeno social complexo, definido como a interrupção no ciclo de estudos (BAGGI; LOPES, 2010). A evasão no ensino de nível superior é um problema que afeta de forma significativa o resultado dos sistemas educacionais. As perdas de estudantes que iniciam, mas não se formam são desperdícios sociais, acadêmicos e econômicos. No setor público se torna recursos públicos investidos sem retorno e no setor privado é uma significativa perda de receitas. Em ambas as situações a evasão se torna uma fonte de ociosidade de professores, funcionários, equipamentos e espaço físico (SILVA FILHO et al., 2007).

Buscando a integração no mercado de trabalho, há uma alta demanda em cursar o nível superior, porém muitos alunos que entram nas faculdades desistem do curso antes de se formarem. Quando se analisa a evasão em faculdades particulares a razão mais apontada é a dificuldade financeira, pois os custos para se manter na faculdade são altos (além de pagar as mensalidades, há despesas com livros, locomoção, etc.). Mas, este motivo apontado não existe em faculdades públicas, pois não há mensalidades a serem pagas, de modo que em geral os gastos mais freqüentes são com locomoção e apostilas (MORAES; THEÓPHILO, 2007). 
Pode ocorrer evasão universitária por vários motivos: trabalho, doença grave ou morte, transferência de domicílio, etc. Muitos alunos têm que dividir seu tempo entre a faculdade e o trabalho e são vencidos pelo cansaço e, ainda, optando pelo dinheiro necessário à sobrevivência. Outros são afetados com o problema da moradia, tendo que arcar com o alto preço dos aluguéis ou das passagens, sem falar no tempo despendido por aqueles que moram longe da faculdade, podendo levar a evasão universitária e ao baixo rendimento dos alunos (MORAES; THEÓPHILO, 2007).

Conforme Silva Filho et al (2007), um dos principais fatores que desestimulam os acadêmicos e os levam a evasão são: questões de ordem acadêmica como dificuldade em disciplinas e notas baixas, a expectativa do aluno em relação ao curso e sua formação e a integração do aluno com a instituição. Para estes pesquisadores, os índices de evasão acadêmica em uma dada Instituição de Ensino Superior - IES podem ser mensurados ao se estabelecer a relação entre a turma estudada, considerando-se: o ano de formação da mesma o número de acadêmicos iniciantes e o número de acadêmicos concluintes. Em caso de cursos semestrais, argumentam os autores, o cálculo se baseia no semestre de início e semestre de conclusão da turma, cuja fonte de informações se caracteriza no banco de dados de registros e controles acadêmicos das instituições.

Um estudo sobre a evasão no curso de Ciências Contábeis foi realizado na Universidade Federal de Pernambuco - UFPE, com o objetivo principal de estudo e análise dos fatores que levaram os alunos de Ciências Contábeis a evasão nos períodos de 1999 a 2008. Tal estudo teve como objetivos específicos: levantar a lista dos alunos que desistiram do curso no período mencionado, aplicar questionário com os desistentes do curso para identificar as possíveis causas da evasão e analisar com base na revisão teórica o fatores considerados motivadores para evasão (VASCONCELOS; et al., 2011).

No estudo de Vasconcelos et al.(2011) foram aplicados questionários via e-mail a 413 alunos evadidos do curso de Ciências Contábeis na UFPE, porém apenas $26 \%$ retornaram o questionário respondido o que corresponde a 107 questionários para serem analisados e tabulados. Através dos resultados alcançados com o questionário foi possível montar o perfil dos alunos evadidos do curso, sendo que em sua maioria a evasão foi mais freqüente entre o sexo masculino, representando 71,09\% dos respondentes. Outro elemento interessante se refere ao período cursado, que apontou 49,04\% dos alunos estudantes do período matutino. Em relação à renda familiar dos evadidos na época em que cursavam Ciências Contábeis: 9\% tinham renda de até $\mathrm{R} \$ 500,00,55 \%$ tinham renda entre $\mathrm{R} \$ 1.500,00$ a $\mathrm{R} \$ 3.000,00,18 \%$ 
constavam com renda de $\mathrm{R} \$ 3.000,00$ a $\mathrm{R} \$ 6.000,00$ e $9 \%$ estavam com renda acima de $\mathrm{R} \$$ 6.000,00. O mesmo estudo se constatou que $91 \%$ dos alunos respondentes ao questionário, trabalhavam e estudavam na época de sua evasão. Quando perguntado sobre o motivo para a evasão do curso: 9\% dos respondentes apontaram que a forma como as disciplinas estavam sendo ministradas não atendiam às suas expectativas, $18 \%$ descobriram que não tinham vocação para o curso e $73 \%$ responderam outros motivos (não foi descrito na pesquisa estes outros motivos causadores da evasão). As demais alternativas quais sejam: começar a trabalhar em horário incompatível com o curso, a dificuldade em algumas disciplinas e o fato de morarem longe da universidade não configurou motivo para a evasão dos respondentes, pois não foram indicadas pelos mesmos. Quanto ao fato dos evadidos pesquisados já terem ou não cursado algum outro curso de nível superior, 73\% responderam afirmativamente já terem cursado o nível superior e $27 \%$ responderam não haviam cursado nenhum curso de nível superior.

O estudo de Martins (2007) também teve como foco a evasão, a autora buscou conhecer os motivos pelos quais os alunos evadem dos cursos de graduação de uma IES privada do estado de Minas Gerais. Foi delimitado o período de 2002 a 2006 das turmas dos cursos de: Direito, Sistemas de Informação, Serviço Social e Administração de uma IES privada que conta com quatro campi na cidade de Montes Claros/MG. A listagem dos evadidos somou 1270 alunos, porém destes somente 129 responderam ao questionário proposto. A investigação de Martins (2007) constatou que dos cursos analisados o que possui maior taxa de evasão é o curso de Sistemas de Informação com 41,65\% e o curso com menor taxa de evasão foi o curso de Serviço Social com 22,08\%. A evasão média dos cursos foi de $33,96 \%$ (relação entre os ingressantes dos cursos analisados e os evadidos do mesmo). $\mathrm{O}$ ano com maior taxa de evasão foi o ano de 2005, em cujo ano evadiram-se 31,8 \% (base com os 129 alunos respondentes), sendo o quinto semestre o período em que a taxa de evasão foi maior entre os respondentes, registrando $12,5 \%$.

Através das respostas do questionário aplicado por Martins (2007) foi delineado o perfil dos 129 alunos que atenderam ao questionário da pesquisa. Em relação ao gênero dos respondentes 50,5\% são do sexo masculino e 49,5\% são do sexo feminino, uma distribuição praticamente igualitária. Em relação à faixa etária verificou-se que 51,16\% dos entrevistados tinham até 25 anos e 19,38\% tinham mais que 35 anos. Quanto à predominância do estado civil na época de evasão dos cursos $62,8 \%$ responderam que estavam solteiros e 27,9\% 
responderam que seu estado civil era casado $(9,3 \%$ abrange: separado, desquitado, divorciado viúvo).

Ainda no mesmo estudo verificou-se que $79,1 \%$ residiam na cidade do campus e 20,9\% em cidades vizinhas, cujo dado mostra que não é motivo para a evasão o fato de não morar na cidade do campus. Em relação à renda familiar, 31\% dos entrevistados tem renda de até 3 salários mínimos, 24\% tem renda de 3 a 6 salários mínimos e $45 \%$ tem renda a cima de 6 salários mínimos. Dos 129 respondentes, 36,04\% não estavam inseridos no mercado de trabalho e 63,06\% estavam trabalhando. Um fator de extrema importância foi demonstrado através das respostas do questionário, apontando que 74,4\% dos evadidos não reprovaram em nenhuma disciplina, portanto a reprovação e a dependência em disciplinas não foi fator para a evasão naquele estudo.

A pesquisa de Martins (2007) concluiu acerca dos principais fatores que levaram os entrevistados à evasão: o valor elevado da mensalidade para de 52,7\% dos entrevistados; dificuldades financeiras momentâneas para 41,9\%; falta de financiamento com $38 \%$ de respostas e mudança de interesse, opção de vida e indecisão profissional como opção de $24,1 \%$ dos respondentes. Estes fatores são semelhantes entre si e estão ligados as condições financeiras dos alunos evadidos, ou seja, não foram fatores isolados que levaram os alunos a desistência do curso, assim, um fator se relaciona a outro.

Outro estudo a respeito da evasão no ensino superior foi realizado por Miranda (2006), o qual tinha como objetivo geral analisar o fenômeno da evasão em cursos de Administração de uma IES privada com quatro campi no estado de Espírito Santo (não fora identificada a IES, sendo chamada pela autora por Faculdade A, B e C sendo que a primeira tem dois campi). Contava também com os objetivos específicos auxiliares: identificar os fatores que levam os alunos de uma IES privada a evasão e apontar uma solução para o fenômeno em estudo. Sua amostra de pesquisa não privilegiou a coleta de dados a partir dos alunos evadios, mas sim foram entrevistadas 12 pessoas responsáveis pela administração nos quatro campi que a IES possui no estado citado e também foi feito um estudo documental, com dados e documentos fornecidos pela IES. O período analisado foi de 1999 (ano de criação da faculdade) a 2005. Através da pesquisa documental traçou-se o perfil dos alunos evadidos (ficha de inscrição que aluno preenche ao se matricular na faculdade), verificando que em relação ao estado civil a predominância da evasão foi entre os declarados solteiros. Em se tratando de gênero a evasão foi freqüente entre o sexo feminino e quanto à faixa etária se evidenciou que os desistentes em sua maioria tinham até 25 anos de idade. A oferta de cursos 
de Administração por ouras IES, a falta de estágio por parte das empresas e problemas financeiros foram os fatores evidenciados como causadores da evasão na IES em estudo.

Foi elaborado por Moraes e Theóphilo (2002) um estudo sobre a evasão no curso de Ciências Contábeis na Universidade Estadual de Montes Claros (UNIMONTES), cujo objetivo principal dos autores era demonstrar os fatores que levaram os acadêmicos a desistência do curso no período de 1993 a 2002. Foram realizadas entrevistas com 105 evadidos porém somente 24 responderam. Através das respostas dos mesmos foi possível chegar aos seguintes ao perfil: tinham idade entre 21 e 25 anos quando ingressaram no curso, possuíam renda familiar superior a 10 salários mínimos, residiam perto da universidade, trabalhavam, não tinham e nem estavam cursando outro curso superior; cursaram o $2^{\circ}$ grau em escolas particulares e eram em sua maioria do sexo masculino. Quanto aos fatores que ocasionaram a evasão, nota-se pelas repostas dos entrevistados que: 50\% destes descobriram que não eram vocacionados para o curso; 30\% começaram a trabalhar em horário incompatível com o horário do curso. Sobre a forma como as disciplinas eram ministradas $8 \%$ responderam que a didática utilizada não atendia às suas expectativas, $8 \%$ descobriram que não eram vocacionados pelo curso e a forma como foi ministrada as disciplinas do curso não atenderam às suas expectativas. Em minoria $4 \%$ dos entrevistados descobriram que não eram vocacionados pelo curso, a forma como foi ministrada as disciplinas do curso não atenderam às suas expectativas e encontraram dificuldades no conteúdo de algumas matérias.

\section{METODOLOGIA}

Os métodos de pesquisa utilizados na execução deste trabalho de investigação podem ser compreendidos quanto aos fins e quanto aos meios. Tomando os fins a que serve a pesquisa ela se caracteriza como pesquisa exploratória, pesquisa descritiva e pesquisa explicativa. Já quanto aos meios pode-se compreendê-la como pesquisa de campo, pesquisa telematizada, pesquisa documental e pesquisa bibliográfica.

A pesquisa exploratória é aplicada em um tema pouco conhecido, sendo realizada em ambientes onde o fenômeno ainda não foi estudado, de forma que visa esclarecer o problema para que o mesmo possa se tornar mais explícito e familiar ao pesquisador . Em se tratando de pesquisa descritiva, assim se caracteriza por evidenciar as características e variáveis de determinada população ou fenômeno a ser investigado, é um dos métodos de pesquisa mais utilizados pelo fato de conseguir descrever, o mais próximo da precisão, as características de um grupo de amostra, como por exemplo, a distribuição do grupo por: sexo, idade, nível de escolaridade, etc. A investigação explicativa tem como principal finalidade identificar os 
fatores que contribuem para que os fenômenos venham a acontecer. Este tipo de pesquisa é o que mais aprofunda o conhecimento da realidade, pois tem o objetivo de descrever o porquê e a razão das coisas ou fatos (VERGARA, 1997; GIL, 2010).

A pesquisa de campo é uma investigação que se desenvolve em um ambiente onde ocorre o fenômeno a ser estudado, podendo valer-se de entrevistas, questionários, testes e observações como ferramentas de coleta de dados. É uma forma de coleta que permite obter e registrar as características e dados do grupo de amostra. A técnica de pesquisa telematizada visa obter informações em meios que combinam o uso de computador e de telecomunicações, de forma que o exemplo mais prático para este tipo de pesquisa é a busca e pesquisa de informações através da internet (VERGARA, 1997; OLIVEIRA, et al., 2003).

Para esclarecimentos acerca da pesquisa documental é possível afirmar que se trata de uma forma de coletar dados através de documentos geralmente escritos e arquivados em papéis, porém reservando-se a possibilidade das estratégias inovadoras e tecnologia dos mais variados documentos disponibilizados em meios eletrônicos. Documento é qualquer objeto que possa comprovar a matéria contida, como livros, jornais, revistas, teses, diários memorandos, ofícios, balancetes, anais, microfilmes, vídeos, mapas, fotografias, escrituras, certidões, etc. Geralmente os documentos são arquivados em empresas, órgãos públicos e organizações diversas (VERGARA, 1997; GIL, 2010; OLIVEIRA, et al., 2003).

A pesquisa bibliográfica seguindo os mesmos autores, tem base em materiais publicados, tradicionalmente em fontes impressas como livros, jornais, revistas, etc, tendo como princípio a disseminação de informações. Este tipo de pesquisa passa a incluir fontes com outros tipos de formatos além dos tradicionalmente publicados em forma de papéis, como discos, fitas magnéticas, CD's e até mesmo materiais disponíveis nas redes sociais, como a internet. As fontes bibliográficas permitem ao pesquisador conhecimento sobre o assunto a ser estudo sob a percepção de diversos autores, assim servirão de base para a manipulação de dados e análises a serem realizadas.

Ao se referirem a estudo de caso conforme Vergara (1997) e Gil (2010), trata-se de estudo realizado quando se pretende explicar ou demonstrar as variáveis causas de determinado fato ou fenômeno, os quais referem-se a situações complexas quando não é possível utilizar técnicas de levantamento e experimentos específicos. Geralmente estes estudos são voltados a grupo de pessoas onde o principal objetivo é aprofundar e detalhar o fenômeno em questão. 
Quanto ao instrumento de coleta de dados utilizados nesta investigação, questionário, se refere a técnica de pesquisa constituída de perguntas relacionadas e ordenadas com foco em um tema central, que são respondidas pelo público alvo sem a presença do investigador/entrevistador. É uma técnica muito utilizada, pois a partir dos dados obtidos é possível mensurar cada resposta, unindo a opinião de vários entrevistados (OLIVEIRA, et al., 2003). O questionário aplicado contou com 17 questões, sendo 15 de respostas fechads e 2 abertas. Foi elaborado de maneira que através das respostas se trace o perfil dos evadidos e demonstre os principais motivos que os levaram a evasão. O questionário foi aplicado ao público alvo no período de Janeiro a Março de 2012.

Diante do exposto este estudo foi realizado no campus da UNEMAT de Tangará da Serra/MT, onde o tema não foi estudado. Foi delimitado estudo com os acadêmicos ingressantes no período de 2008/1 a 2011/2. A listagem dos alunos evadidos do curso no período aqui citado foi obtida do banco de dados da Supervisão de Apoio Acadêmico (SAA), setor que funciona nas dependências do Campus. A partir desta lista, com 67 acadêmicos evadidos, os contatos foram realizados via e-mail, telefone e visitas aos ex-alunos, solicitando que respondessem ao questionário proposto.

Os dados foram organizados em forma de tabelas e gráficos que serão analisados a luz dos referenciais teóricos de a pesquisas já desenvolvidas sobre o tema.

Diante dos conceitos apresentados anteriormente e com base na coleta de dados pôdese chegar à discussão dos resultados que serão apresentados a seguir, com base nas respostas de 32 dos entrevistados, o que corresponde a 47,76\% dos acadêmicos evadidos, que conforme dados da SAA - Supervisão de Apoio Acadêmico do campus totalizam 67 no período em estudo. A dificuldade de contato com os evadidos também foi registrada em vários trabalhos, como o de Vasconcelos et al.(2011) que conseguiu retorno de 26\%, Martins (2007) com retorno de 10,16\% dos entrevistados, assim como Moraes e Theóphilo (2002) que alcançaram retorno de 22,86\%. Diante disso um retorno de 47,76\% que foi o obtido por esta pesquisa pode ser considerado um número vantajoso quando considerado as demais pesquisas.

\section{ANÁLISE E DISCUSSÃO DE RESULTADOS}

Na UNEMAT de Tangará da Serra/MT o número de matriculados no curso de Ciências Contábeis conforme dados disponíveis no site do curso, é um número bastante vantajoso visto que são oferecidas 50 vagas por turma. No semestre 2008/1 foram registrados 347 alunos matriculados, em 2009/1 as matriculas confirmadas somaram em 403 e em 2011/1 o número de matriculados aumentou e totalizou 406. O índice de evasão também aumentou 
conforme decorrência dos semestres, em 2008/1 o índice de evasão era de 1,73\%, em 2009/1 este índice foi para 4,47\%. Em 2010/1 este índice estava em 5,19\%, no semestre 2011/1 o índice apontou evasão em 5,42\%, fechando o ano de 2011 seu segundo semestre foi marcado por um índice de evasão de 6,4\%. Estes índices de evasão referem-se do total de alunos matriculados considerando os 8 semestres de curso.

O quadro 1 representa as características dos entrevistados a partir de suas respostas quanto a sexo, onde cursaram o ensino médio, se optaram pelo PIER ao se inscreverem no vestibular, idade atual, idade quando evadiram e renda mensal à época da evasão.

Tabela 1: Caracterização dos entrevistados.

\begin{tabular}{|c|c|c|c|c|c|}
\hline \multicolumn{2}{|l|}{ Sexo } & \multicolumn{2}{|c|}{ Ensino Médio } & \multicolumn{2}{|c|}{ Optante pelo PIER? } \\
\hline Feminino & $66 \%$ & Escola pública & $88 \%$ & Sim & $28 \%$ \\
\hline Masculino & $34 \%$ & $\begin{array}{l}\text { Escola particular } \\
\text { Parte em escola púl } \\
\text { particular }\end{array}$ & $\begin{array}{l}9 \% \\
3 \% \\
\end{array}$ & Não & $72 \%$ \\
\hline \multicolumn{2}{|l|}{ Idade atual } & \multicolumn{2}{|c|}{ Idade quando evadiu do curso? } & \multicolumn{2}{|c|}{$\begin{array}{l}\text { Renda mensal quando } \\
\text { evadiu do curso? }\end{array}$} \\
\hline 17 a 22 anos & $31 \%$ & 17 a 22 anos & $44 \%$ & 1 salário & $44 \%$ \\
\hline 23 a 27 anos & $44 \%$ & 23 a 27 anos & $41 \%$ & 2 salários & $25 \%$ \\
\hline 28 a 32 anos & $19 \%$ & 28 a 32 anos & $9 \%$ & 3 salários & $12 \%$ \\
\hline 33 a 38 anos & $6 \%$ & 33 a 38 anos & $6 \%$ & Acima de 3 salários & $19 \%$ \\
\hline Acima de 39 anos & 0 & Acima de 39 anos & 0 & & \\
\hline
\end{tabular}

Fonte: Dados da pesquisa.

Quanto ao gênero dos entrevistados, 66\% são do sexo feminino e 34\% são do sexo masculino. Nota-se que o número de mulheres que evadiram do curso de Ciências Contábeis é superior ao número de homens. Os dados acima registrados se espelham às características encontradas no trabalhos de Miranda (2006) e se opõem ao perfil encontrado por Vasconcelos et al.(2011) no qual 71,09\% dos respondentes eram do sexo masculino. Em Martins (2007) a maioria, quase imperceptível, 50,5\%, é do sexo masculino.

Quando perguntado sobre onde cursaram o Ensino Médio, a maioria respondeu ter cursado em escola pública, totalizando $88 \%$ das respostas, sendo que a minoria, de $9 \%$, responderam ter cursado em escola particular. Dos entrevistados, 3\% cursaram o ensino médio parte em escola pública e parte em escola particular. Tais dados não se associam aos respondentes da pesquisa de Moraes e Theóphilo (2002), onde os evadidos em sua maioria eram procedentes de escolas particulares.

Pelas respostas observa-se que dentre os entrevistados $72 \%$ não optaram por se inscrever no vestibular concorrendo as vagas do Programa de Inclusão Étnico Racial (PIER). Apenas 28\% utilizaram das cotas deste programa para ingresso no ensino superior. Por estas 
respostas observa-se que o programa de cotas foi pouco utilizado dentre os evadidos, sendo este um dado que merece ser explorado em pesquisas futuras, já que as políticas públicas vem incentivando o ingresso na universidade de candidatos que pertençam a grupos tradicionalmente excluídos da condição de acesso ao ensino superior.

Quanto a faixa etária no momento das respostas ao questionário dadas pelos entrevistados, pode-se afirmar que $44 \%$ dos evadidos do curso informaram ter idade entre 23 a 27 anos, $31 \%$ entre 17 a 22 anos de idade, 19\% na faixa de 28 a 32 anos e a minoria $6 \%$ afirmaram ter entre 33 a 43 anos. Nenhum dos evadidos do curso informaram ter idade acima de 43 anos. Ao serem questionados sobre a idade que tinham à época em que evadiram do curso, $44 \%$ dos ex-alunos responderam que tinham entre 17 a 22 anos e $41 \%$ estavam entre 23 a 32 anos. Nenhum dos evadidos respondeu ter idade acima de 43 anos quando evadiu do curso. Somando os dados desta pesquisa, a maioria dos respondentes (85\%) tinham até 32 anos quando evadiu do curso, cujo dado coincide com a faixa etária encontrada por Miranda (2006) onde a maioria dos respondentes tinha idade até 27 anos e com o resultado de Martins (2007) onde $51,16 \%$ dos entrevistados tinham até 25 anos.

Em se tratando do aspecto financeiro dos sujeitos desta pesquisa grande parte dos entrevistados tinham renda mensal de 1 salário mínimo, correspondendo a $44 \%$ dos respondentes; $25 \%$ tinham renda de 2 salários mínimos e 19\% tiham renda acima de 3 salários mínimos. A parcela menor das respostas coube aos que informaram renda de 3 salários mínimos, num total de $12 \%$. Esse resultado se distancia significativamnte dos resultados de Vasconcelos et al.(2011), que em seu estudo demonstrou que 55\% tinham renda entre $\mathrm{R} \$$ 1.500,00 a R\$ 3.000,00 valor, representando aproximadamente de 4 salários mínimos. Também se distancia dos resultados de Moraes e Theóphilo (2002), em que os evadidos possuíam renda familiar superior a 10 salários mínimos. Distancia-se da pesquisa de Martins (2007) onde demonstrou que 45\% dos entrevistados informaram renda a cima de 6 salários mínimos.

Outro fator de grande relevância para este estudo refere-se ao semestre do curso que o acadêmico cursava à época em que acabou desistindo. Neste sentido, os dados coletados sinalizam para $47 \%$ dos entrevistados que desistiram do curso ainda no primeiro semestre letivo e $31 \%$ informaram que estavam no segundo semestre. Ainda é considerável o índice de $22 \%$ que evadiram entre o $3^{\circ}$ a $5^{\circ}$ semestre. Por estes dados comprova-se que $78 \%$ dos exalunos desistiram ainda no primeiro ano de faculdade. Vale ressaltar que nenhum dos 
entrevistados evadiram do curso entres o $6^{\circ}, 7^{\circ}$ e $8^{\circ}$ semestre, conforme representado na figura 1.

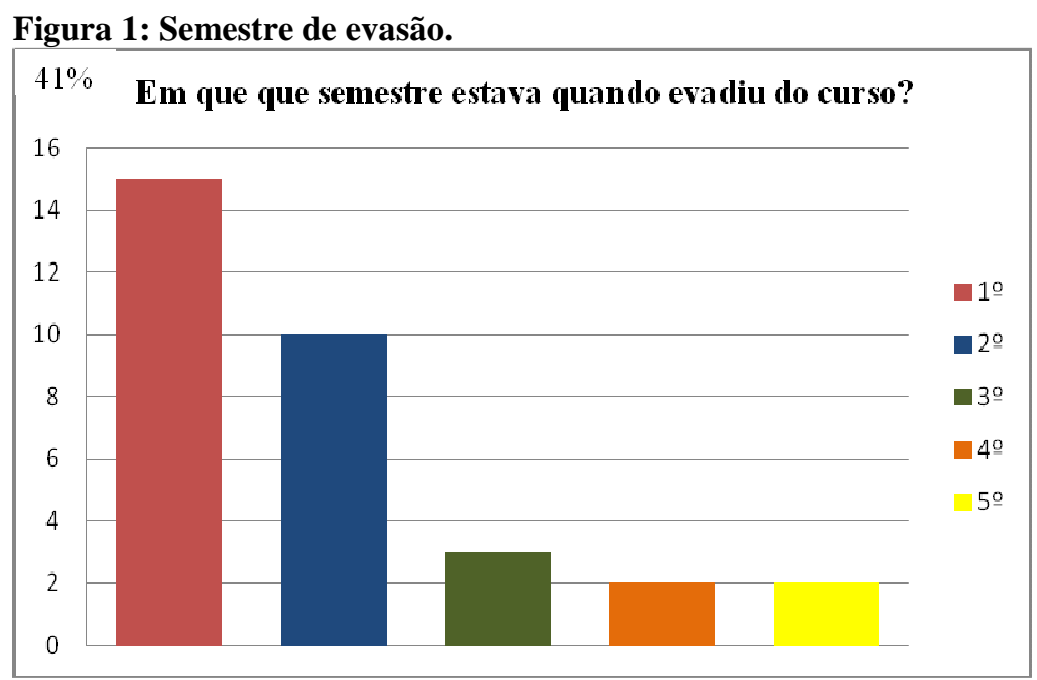

Fonte: Dados da pesquisa.

Este dado se opõe ao encontrado por Martins (2007) onde sua pesquisa aponta que o semestre em que a taxa de evasão foi maior registrando $12,5 \%$ foi o $5^{\circ}$ semestre. $O$ fato da desistência do curso ocorrer ainda nos primeiros semestres deve se configurar objeto de reflexão por parte da gestão do curso. Vale lembrar que os semestres iniciais se caracterizam por oferta de disciplinas que fundamentam o curso, sendo que as disciplinas específicas da área de formação se apresentam com menor carga horária, o que pode se configurar em condição para desestímulo do acadêmico.

Quanto a distância das residências dos ex-alunos até a universidade, a pesquisa aponta que $63 \%$ dos evadidos moravam longe da UNEMAT e $31 \%$ moravam muito longe. Residiam razoavelmente perto da universidade apenas 6\% dos entrevistados e nenhum deles residia perto da universidade. Moraes e Theóphilo (2002) também levantaram esta questão e em sua pesquisa e a maioria dos respondentes somando $58 \%$ residiam perto da universidade. É importante considerar que o campus da UNEMAT está localizado a uma distância de aproximadamente $8 \mathrm{~km}$ do centro da cidade, necessitando que os acadêmicos se utilizem de transporte público ou veículos particulares para seu deslocamento até a universidade. 
Fatores que produzem evasão acadêmica no curso de ciências contábeis da UNEMAT de Tangará da Serra/MT

Figura 2: Distância das residências dos evadidos até a universidade.

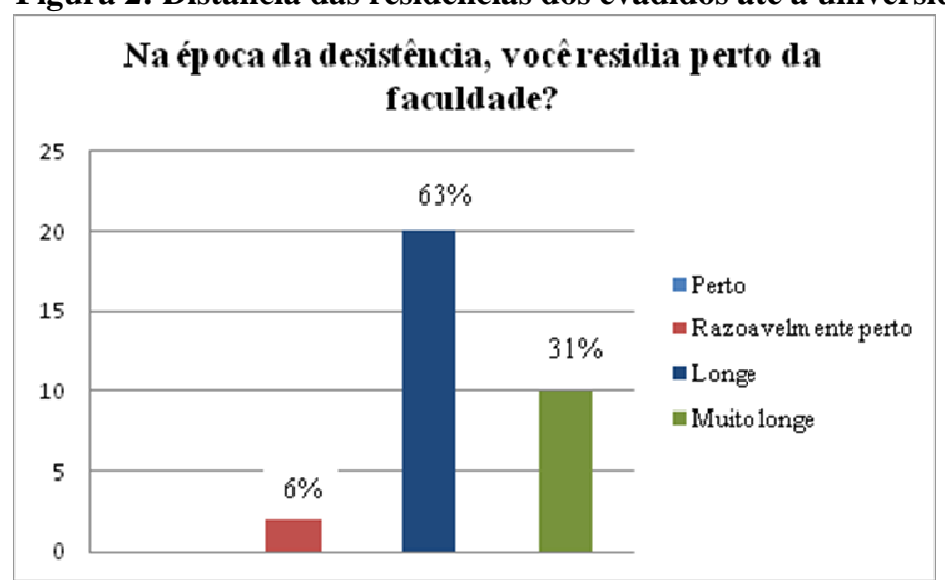

Fonte: Dados da pesquisa.

Sobre estar ou não trabalhando na época de início do curso, $78 \%$ responderam afirmativamente estavam trabalhando quando ingressaram no curso e $22 \%$ não estavam trabalhando ao iniciarem o curso, conforme dados apresentados na figura 3.

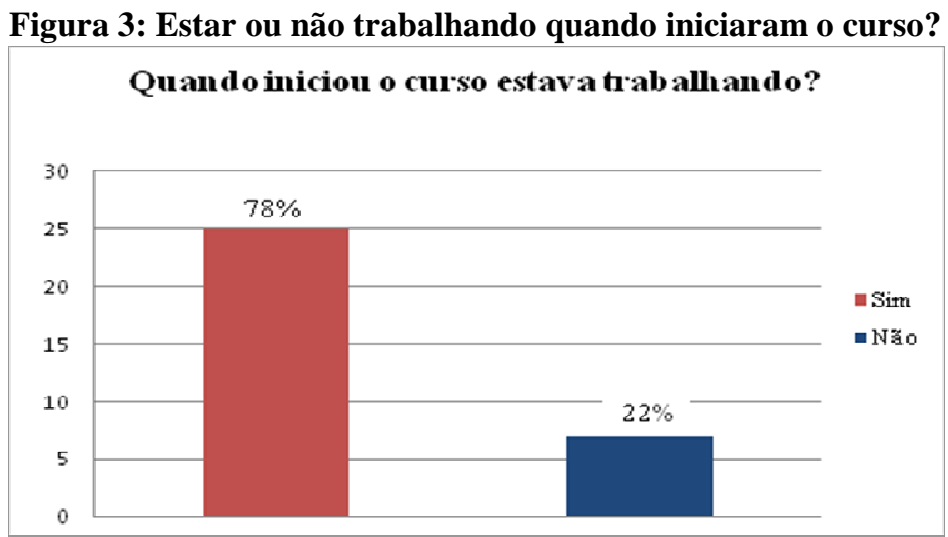

Fonte: Dados da pesquisa.

Quando perguntado se na época da evasão do curso estavam trabalhando, coincidentemente obte-se os mesmos índices apresentados na figura 4, 78\% dos evadidos estavam trabalhando quando desistiram do curso e $22 \%$ não estavam trabalhando, conforme expressa a figura 4.

Figura 4: Estar ou não trabalhando na época da evasão.

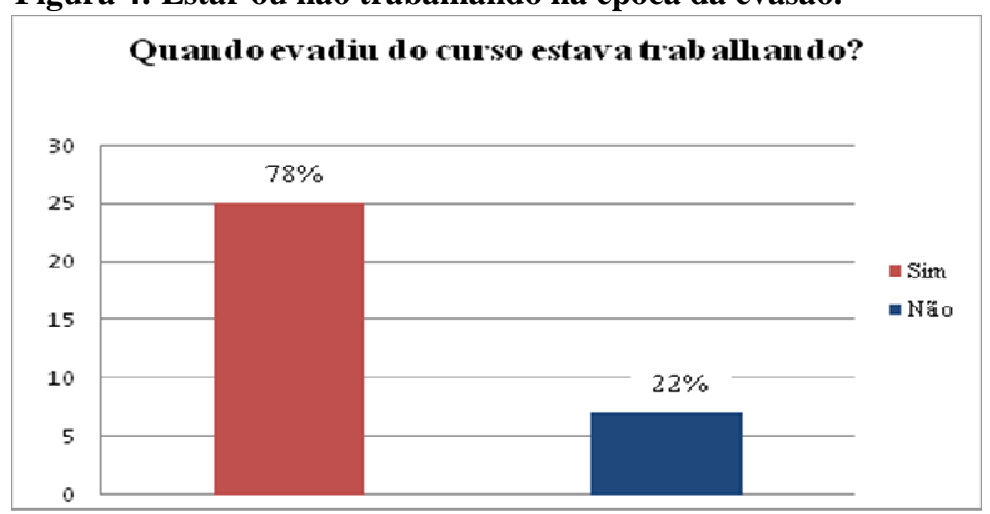

Fonte: Dados da pesquisa. 
Estes dados indicam que ao iniciarem o curso já exerciam atividade profissional, a jornada de atividades profissionais e a jornada acadêmica já ocorria desde o início do curso. Esta característica também foi encontrada por Vasconcelos et al .(2011), e sua pesquisa apontou que $91 \%$ dos evadidos trabalhavam e estudavam na época de sua evasão. Martins (2007) evidenciou que $63,06 \%$ dos alunos estavam trabalhando quando evadiram.

O fato de ter ou não cursado outro curso de nível superior também foi questionado, cujas respostas estão na figura 5.

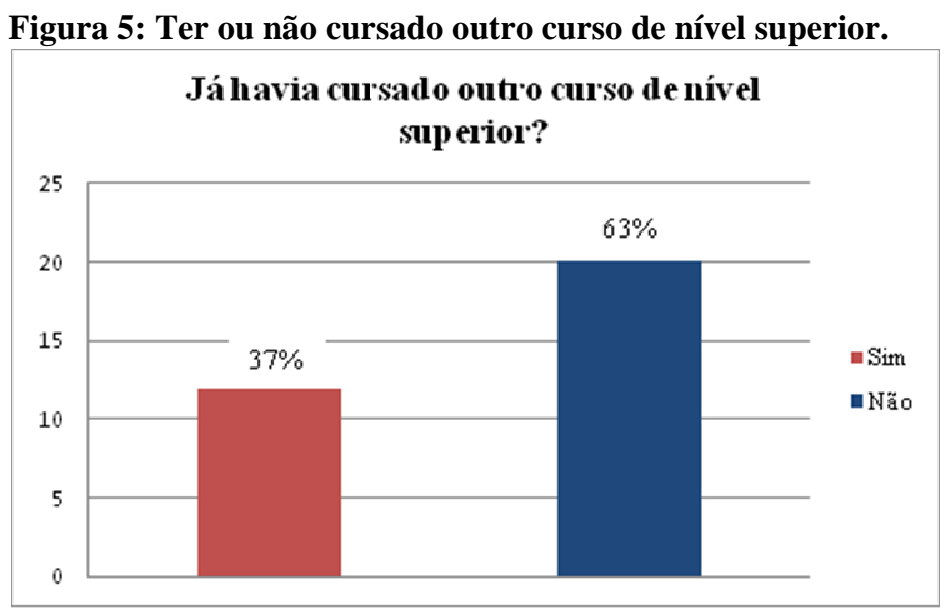

Fonte: Dados da pesquisa.

Pode-se observar que 63\% dos evadidos do curso de Ciências Contábeis da UNEMAT de Tangará da Serra/MT, participantes deste estudo, responderam que não haviam se graduado em nenhum outro curso. É importante sinalizar que dos entrevistados, 37\% afirmaram que já eram graduados em outro curso. Esta questão também foi levantada na pesquisa de Moraes e Theóphilo (2002) em cujo estudo a maioria dos respondentes afirmaram que não tinham e nem estavam cursando outro curso superior. Difere-se do resultado encontrado por Vasconcelos et al.(2011) sua pesquisa apontou que 73\% dos respondentes já eram graduados em outro curso. Estas respostas podem indicar que o fato de já terem uma graduação desestimula a conclusão de outra formação profissional.

Os fatores que levaram os evadidos a escolherem o curso de Ciências Contábeis para ingressar também foram levados em consideração. Foi apontado como o principal motivo o fato de já se identificar com a profissão de contador com $31 \%$ das respostas. A falta de opção foi apontada por $28 \%$ dos respondentes e $13 \%$ indicaram a influência de familiares e amigos. Também um significativo índice, de 28\%, apontaram outros motivos como: já ter nível técnico em contabilidade, gostar de números e cáculos e dar complemento a graduação realizada anteriormente. 
Figura 6: Fatores que colaborarão pela opção do curso de Ciências Contábeis.

\section{O que o levou a escolha do curso de Ciências Contáb eis?}

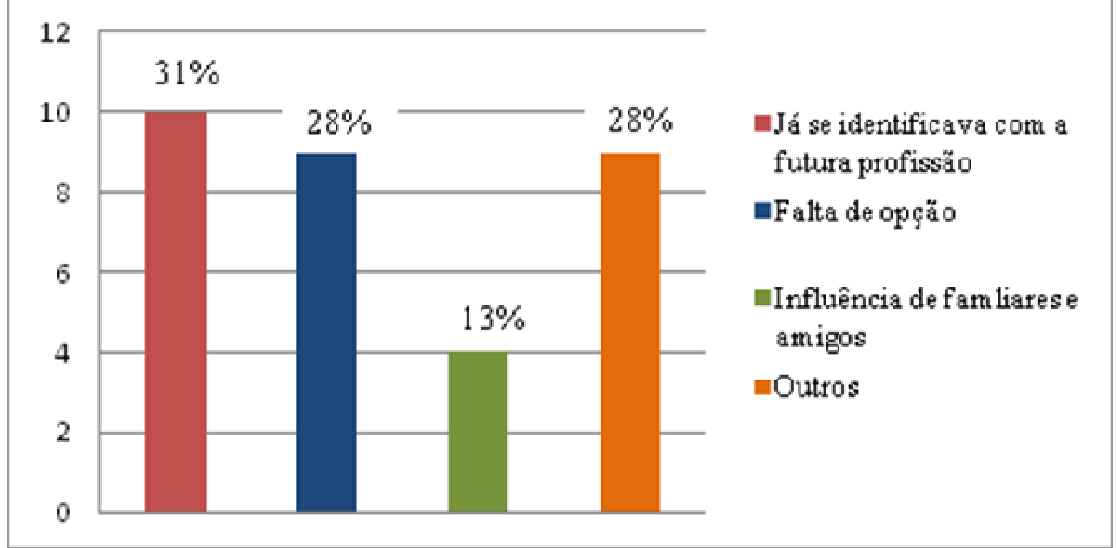

Fonte: Dados da pesquisa.

Quanto ao conhecimento da grade curricular, foi perguntado se ao candidatar-se a vaga no curso de Ciências Contábis tinha conhecimento das disciplinas que cursaria ao longo do curso. Sobre esta questão, 53\% (pouco mais da metade dos evadidos) não buscaram conhecer a grade curricular do curso de Ciências Contábeis e $47 \%$ tinham ciência da grade a cursar.

Figura 7: Ter conhecimento sobre a grade curricular.

\section{Quando optou pelo curso de Ciências \\ Contáb eis buscou conhecer a grade curricular?}

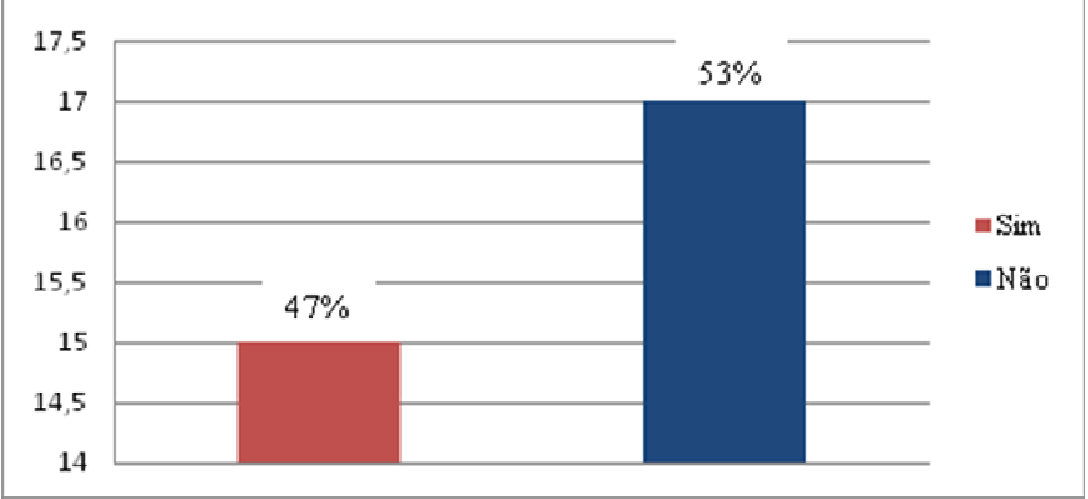

Fonte: Dados da pesquisa.

O fato de reprovar em alguma disciplina, conforme dados apresentados na Figura 8, não pode ser apontado como fator influente para a evasão, $72 \%$ dos entrevistados responderam nunca terem reprovado em qualquer disciplina. Já $22 \%$ dos respondentes reprovaram apenas uma vez e 6\% chegaram a reprovar duas vezes, sendo que nenhum respondente indicou ter reprovado três ou mais vezes. 
Figura8: Reprovação em disciplina.

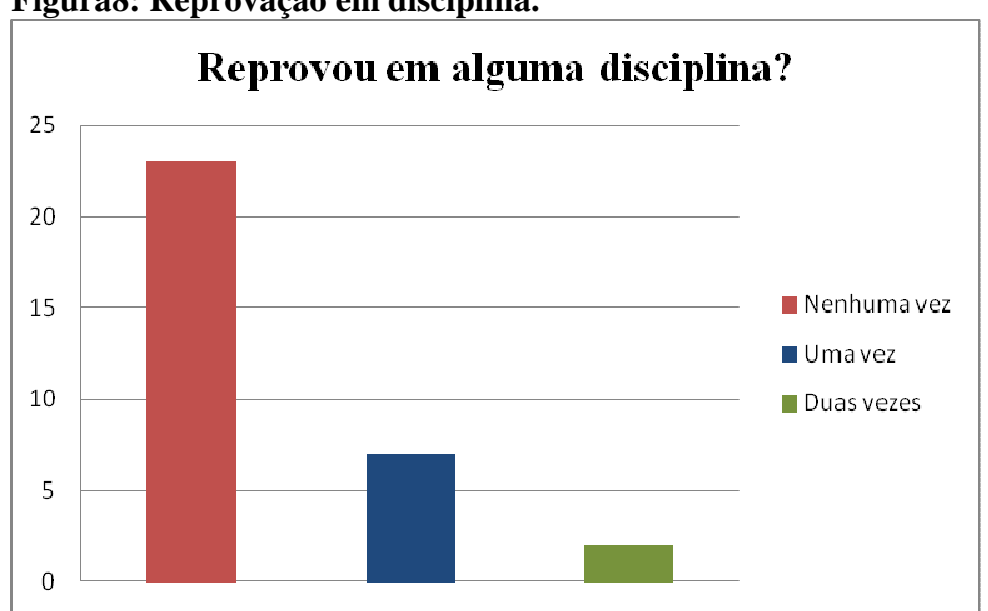

Fonte: Dados da pesquisa.

Os dados acima apresentados são significativos, já que, num primeiro momento, sem estudos criteriosos, pode-se associar a evasão com questões de dependências em disciplinas. A reprovação escolar tem sido tema de intensos debates por educadores brasileiros, que centram seus esforços no combate a reprovação, sendo que nesta pesquisa este não se configura como o fator indicativo da produção da evasão. É importante assinalar que os dados coletados neste estudo conferem com os alcançados por Martins (2007), cuja pesquisa apontou que $74,4 \%$ dos evadidos não reprovaram em nenhuma disciplina.

Para identificar mais precisamente os fatores motivadores da evasão acadêmica, foi proposta uma questão no questionário onde os respondentes poderiam escolher mais que uma alternativa, a fim de identificar com maior clareza os fatores que os influenciaram a evadir do curso. As respostas resumem-se na tabela a seguir:

Figura 2: Fatores motivadores para a evasão acadêmica.

\begin{tabular}{|c|c|}
\hline Fatores motivadores para a evasão acadêmica & $\begin{array}{l}\mathrm{N}^{\circ} \text { de } \\
\text { respostas }\end{array}$ \\
\hline Motivos de trabalho & 17 \\
\hline $\begin{array}{l}\text { Não tinha tempo para estudar e fazer os trabalhos } \\
\text { curriculares }\end{array}$ & 9 \\
\hline Descobriu que não tinha vocação para o curso & 6 \\
\hline Mudança de cidade/estado & 5 \\
\hline Dificuldade em algumas disciplinas & 5 \\
\hline O curso não era o que imaginava & 4 \\
\hline $\begin{array}{l}\text { Não gostou da forma de como as disciplinas eram } \\
\text { ministradas }\end{array}$ & 4 \\
\hline Motivos financeiros & 4 \\
\hline Saúde & 2 \\
\hline Reprovação em disciplinas & 2 \\
\hline Motivos familiares & 2 \\
\hline Disciplina sem relação com o curso & 1 \\
\hline Outros & 2 \\
\hline
\end{tabular}

Fonte: SAUBERLICH, 2012. 
O fator mais indicado para a evasão acadêmica, com 17 respostas, foi a questão de trabalho. O segundo fator mais apontado pelos entrevistados se refere ao tempo para estudo, de forma que 9 entrevistados afirmaram não ter tempo para estudar e fazer os trabalhos curriculares. Numa terceira ordem de importância, 6 respostas, foram atribuídas a descobrir que não tinha vocação para o curso. Outros fatores apontados com 5 sinalizações: mudança de cidade ou estado, e dificuldade em algumas disciplinas. Com 4 respostas: o curso não era o que imaginava, não gostou da forma de como as disciplinas foram ministradas e motivos financeiros. Os motivos, para 2 dos respondentes, se referem a: questões de saúde, reprovação em disciplina e motivos familiares e com 1 indicação o fato de alguma disciplina não ter relação com o curso. Outros motivos foram indicados através de 2 respostas dissertativas como: não conseguir aproveitamento de matérias cursadas anteriormente e perda do prazo para rematrículas.

Os fatores apontados como motivadores para a evasão acadêmica coincidem com os fatores encontrados na pesquisa de Silva Filho, et al. (2007), que apontou como fatores desestimulantes para os acadêmicos os levando à evasão, como dificuldade em disciplinas e notas baixas, a expectativa do aluno em relação ao curso e sua formação. O trabalho de Vasconcelos et al.(2011) apontou características semelhantes a esta pesquisa como: por parte dos evadidos descobrir que não tinham vocação para o curso, apontaram que a forma como as disciplinas estavam sendo ministradas não atendiam às suas expectativas. Também na pesquisa de Moraes e Theóphilo (2002) foram encontrados fatores semelhantes como: os evadidos descobrirem que não eram vocacionados para o curso, começaram a trabalhar em horário incompatível com o horário do curso, e ainda que a didática utilizada pelos professores não atendiam às suas expectativas.

Foi deixado em aberto uma pergunta para que os ex-alunos manifestassem em uma palavra ou expressão que significasse a razão que os fizeram desistir do curso e as respostas mais freqüentes foram: com 5 respostas, apontaram motivos de trabalho, com 4 respostas, a falta de tempo para estudar; 3 pessoas responderam desgaste (físico e emocional); arrependimento pela opção do curso com 2 respostas; perda da data para realização das rematrículas para 2 dos respondentes; fazer outro curso e desmotivação também com 2 respostas.

Diante dos estudos e resultados apresentados aponta-se as seguintes sugestões. Em relação aos acadêmicos, que estes busquem conhecer a grade curricular do curso escolhido e que se tenha um contato com a universidade e departamento do curso a ingressar. Seria muito 
interessante e de grande valia que estes assuntos fossem abordados durante o ensino médio e que fossem promovidas palestras de apresentação da universidade, esclarecendo sobre os cursos oferecidos, grades curriculares e principais curiosidades dos estudantes. Tal atividade poderia ser feita em parceira com as escolas. É de suma importância que o candidato ao curso superior conheça o mercado de trabalho do curso escolhido assim como procure conhecer as áreas de atuação de um profissional de Ciências Contábeis.

Em relação ao departamento e aos professores, que tentem acompanhar a evolução e aprendizagem individual dos alunos para que as dúvidas e dificuldades sejam sanadas durante as aulas, para que isto não os desmotive e se torne motivos para a evasão. É imperativo que a Universidade, através de cada departamento, forneça informações mais completas possíveis acerca do curso, tal como, os objetivos de cada disciplina na construção do perfil profissional do acadêmico.

Para pesquisas futuras sugere-se uma abordagem com foco nos alunos egressos na universidade através do PIER, para se conhecer o motivo que os optantes por esse programa evadem do curso, abandonando também este benefício. Esta é uma questão que a universidade também deveria fazer um acompanhamento de tais alunos no decorrer do curso.

\section{REFERÊNCIAS}

BAGGI, Cristiane Aparecida dos Santos. LOPES, Doraci Alves. Evasão e avaliação institucional no ensino superior: uma discussão bibliográfica. Campinas/SP 2010. Disponível em: < http://www.scielo.br/pdf/aval/v16n2/a07v16n2.pdf >. Acesso em: 11 set. 2011.

CARVALHO, L. Nelson. IUDÍCIBUS, Sérgio de. MARTINS, Eliseu. Contabilidade: aspectos relevantes da epopéia de sua evolução. Revista de contabilidade \& Finanças.

Mai/Ago, 2005. Disponível em: < http://www.scielo.br/scielo.php?pid=S1519$70772005000200002 \&$ script=sci_arttext $>$. Acesso em: 09 out. 2011.

COVEST, Diretoria de concursos e vestibulares. Concorrências anteriores. Disponível em: http://concursos.unemat.br/concursos/ >. Acesso em: 19 mar. 2012.

Departamento de Ciências Contábeis - UNEMAT - Tangará da Serra. Histórico. Disponível em: 〈https://sites.google.com/a/unemat.br/cictga >. Acesso em: 22 ago. 2011.

FIGUEIREDO, Sandra. FABRI, Pedro Ernesto. Gestão de empresas contábeis. São Paulo: Atlas, 2000.

FILHO, Roberto Leal Lobo e Silva. MONTEJUNAS, Paulo Roberto. HIPÓLITO,

Oscar.LOBO,Maria Beatriz de Carvalho Melo. A evasão do ensino superior brasileiro.

2007. Disponível em <http://www.scielo.br/pdf/cp/v37n132/a0737132.pdf >. Acesso em: 18 set. 2011.

GIL, Antonio Carlos. Como elaborar projetos de pesquisa. 5 ed. São Paulo: Atlas, 2010.

IUDÍCIBUS, Sérgio de.Teoria da contabilidade. 6 ed. São Paulo: Atlas, 2000.

MARTINS, Cleidis Beatriz Nogueira. Evasão de alunos nos cursos de graduação em uma instituição de ensino superior. Montes Claros, 2007. Disponível em:

<http://www.unipel.edu.br/2011/media/pdf/mestrado/dissertacoes_2007/dissertacao_cleidis_b eatriz_nogueira_martins_2007.pdf $>$ Acesso em: 17 set. 2011. 
MIRANDA, Derlinéa Peçanha Moreira. Gestão da evasão nas instituições de ensino superior privado: um estudo sobre o curso de Administração no estado do Espírito Santo. Rio de Janeiro, 2006. Disponível em: < http://www.ufrrj.br/posgrad/ppgen/06/04.PDF> Acesso em: 20 set. 2011. fatores causadores da evasão no curso de Ciências Contábeis da Universidade Estadual de Mo

MORAES, Júlia Oliveira de. THEÓPHILO, Carlos Renato. Evasão no ensino superior: estudo dos ntes Claros - UNIMONTES. Montes Claros, 2007. Disponível em:

<http://www.congressousp.fipecafi.org/artigos32006/370.pdf >.Acesso em: 12 set. 2011. OLIVEIRA, Antonio Benedito Silva.CECCONELHO, Antonio Renato. BARBOSA, Claudionor Francisco. CÉLICE, Eduardo de Souza. KOUNROUZAN, Márcia Covaciuc. GIORGI Wanny Arantes Bogiovanni. Métodos e técnicas de pesquisa em contabilidade. São Paulo: Saraiva, 2003.

PELEIAS, Ivam Ricardo. SILVA, Glauco Peres da. SEGRETI, João Bosco. CHIROTTO, Amanda Russo. Evolução do ensino da contabilidade no Brasil: uma análise histórica. São Paulo, 2007. Disponível em: <http://www.scielo.br/pdf/rcf/v18nspe/a03v18sp.pdf >. Acesso em: 13 set 2011.

REIS, Aline de Jesus. SILVA, Sema Leal da. SILVA. A história da contabilidade no Brasil. Revista UNIFACS. Vol 11. N. 1. 2007. Disponível em: <http://revistas.unifacs.br/index.php/sepa/article/viewArticle/299> Acesso em: 21 mar 2012. $\mathrm{S} \grave{A}$, Antônio Lopes de. Fundamentos da contabilidade geral. 2 ed. Curitiba: Juruá Editora, 2005.

SÁ, Antonio Lopes de. Teoria da contabilidade. 3 ed. São Paulo: Atlas, 2002.

SANTOS, José Luiz dos. SCHMIDT, Paulo. FERNANDES, Luciane Alves. MACHADO, Nilson Perinazzo. Teoria da Contabilidade: introdutória, intermediária e avançada. São Paulo: Atlas, 2007.

Universidade do Estado de Mato Grosso - UNEMAT - Vestibular. Disponível em: <http://concursos.unemat.br/20121/?link=outros >. Acesso em: 01 nov. 2011. VASCONCELOS, Ana Lúcia Fontes de Souza. SILVA, Márcio Nunes da. MIRANDA. Natali Pereira de. Um estudo sobre as causas da evasão no ensino superior no curso de Ciências Contábeis e Atuarias. Recife, 2011. Disponível em: $<$ http://www.acim2011.org/papers/PT/Controlo\%20de\%20Gestao/Um\%20Estudo\%20sobre\% 20as $\% 20$ Causas $\% 20 \mathrm{da} \% 20$ Evasao $\% 20$ no $\% 20$ Ensino $\% 20$ Superior $\% 20$ no $\% 20 \mathrm{Curso} \% 20 \mathrm{de} \%$ 20Ciencias\%20Contabeis\%20e\%20Atuariais.pdf > Acesso em: 18 set. 2011. VERGARA, Sylvia Constant. Projetos e relatórios de pesquisa em administração. São Paulo: Atlas, 1997. 